\title{
UN «MODELO OPERATIVO» DE URBANISMO MUSULMÁN
}

Por MÍKEL DE EPALZA

Vamos a presentar aquí, como se ha hecho oralmente en las reuniones del grupo de investigación sobre «Urbanismo musulmánn, que tienen lugar con regularidad desde 1983 en diversas localidades alicantinas (Agost. Alicante, Benissa, Jalón, Pego...), un "modelo operativo" amplio y flexible de la ocupación funcional del espacio habitado, en la sociedad musulmana, medieval y actual, con especial relieve, evidentemente en Al-Andalus y el Mágreb.

Como "modelo operativo", es una abstracción, que se da sólo en cada caso concreto, individualizado por múltiples factor particulares, especialmente en tres parámetros: la orografía o situación geográfica del poblado (no es lo mismo una ciudad marítima, que un puerto fluvial o un pie de monte con fuentel, la magnitud demográfica (una gran ciudad o un hábitat rural), el factor temporal ivariaciones de una urbe a través de las vicisitudes políticas de la historia musulmana). Pero en todos los casos, se pretende que quede vigente y aplicado el "modelo operativo". Ese es el nivel de su realidad, a pesar de su doble abstracción: está abstraído racionalmente de realidades concretas diversas $y$ es un modelo abstracto que nunca se da tal cual, en toda su simplicidad, en los casos concretos.

Ese "modelo operativo" tiene dos fuentes u origenes. Primeramente, proviene racionalmente del análisis de numerosos casos concretos, en Al-Andalus, en el Mágreb y en Oriente. Es evidente que citar todas las fuentes bibliográficas no entra en las posibilidades ni el alcance de este trabajo. Lo omitimos, sin dejar de mencionar la deuda global a Torres Balbás y a diversos historiadores y arqueólogos franceses y tunecinos. En segundo lugar, hay que decir que la fuente objetiva de los elementos que hemos seleccionado como constantes en el urbanismo musulmán está en su funcionalidad: necesidades o funciones permanentes producen elementos constantes, que son los que hemos estructurado en nuestro "modelo". Es así un umodelo" abstracto, pero no estático. Corresponde a una realidad activa, con actividades sectoriales constantes.

Es un "modelo operativo", que puede ser útil para la investigación urbanística, en sus diversas facetas (arquitectura, sociología, historia, arqueología, etc.). Al que no le sirva, como explicación, pues que no lo utilice. La práctica del grupo de investigación alicantino muestra que sí puede ser "operativon. Los 
ejemplos del libro colectivo en preparación sobre los baños musulmanes (hammàm/en el País Valenciano o la comunicación sobre el trabajo femenino en los espacios urbanos, presentada en los Cursos Internacionales de Benidorm (1984) y en las $V$ Jornadas de Estudios de la Mujer, de la Universidad Autónoma de Madrid (1985), muestran su utilidad. Es, por otra parte, un «modelo operativon flexible por definición, que admite y requiere continuos reajustes concretos.

Finalmente, en esta pequeña introducción metodológica, hay que indicar la importancia de este tema para la historia de Al-Andalus, la España y Portugal actuales en época árabe.

En efecto, de su historia, ya muerta, sólo quedan fragmentos dispersos, en crónicas y documentos escritos, en elementos materiales arquitectónicos y arqueológicos, en toponimia, etc. Poder situar cada uno de esos elementos gracias a un conjunto modélico coherente, que permita reconstruir la realidad viva pasada, es importantísimo. La realidad viva, aunque diversa, del mundo urbanístico musulmán actual puede ayudar muchísimo para esa reconstrucción, a pesar de las evidentes mutaciones producidas por la modernidad. Es evidente que en esa realidad actual se basa también nuestro "modelo operativo".

Hay que decir también que la sociedad musulmana, desde sus origenes en La Meca y Medina, es esencialmente urbana, basada en una actividad de especialización, complementaridad e intercambio. Tiende pues a extender y reproducir el modelo urbano en toda su área de influencia, aun en las zonas que podríamos considerar ururales». Estudiar éstas sin referencia a las estructuras urbanas, puede llevar a profundas distorsiones, como se ha visto recientemente en la zona valenciana.

Última observación, necesaria aunque obvia: el urbanismo musulmán que presentamos no pretende ser original en todos sus elementos, sobre todo en los esenciales. No se pretende aqui ni mostrar sus orígenes históricos ni privilegiar sus elementos específicos u originales. Se trata de ver sus elementos fundamentales, funcionales y morfológicos, prescindiendo de si son comunes o no con otras civilizaciones.

\section{Tres espacios geográficos y el cerco urbano}

Hay que distinguir, en primer lugar, tres grandes espacios, de ocupación humana desigual: el cerco urbano y lo que encierra, las zonas periurbanas y el campo abierto - bádiya, en Al-Andalus- (esquema $1 .{ }^{\circ}$ ).

El cerco urbano limita el espacio central del hábitat musulmán, él mismo diferenciado, como veremos ulteriormente. Este recinto estará delimitado o formado por un cerco, amplia muralla, en las ciudades, o simplemente pared de las casas y de sus huertos, sin salida exterior y con puertas hacia el interior del pueblo, en los hábitat rurales ("casas-murallas", del esquema 4 b). Las murallas pueden reforzarse con un foso exterior, como lo estaban en Medina. La función defensiva frente al exterior define el cerco urbano, como definirá la casa familiar musulmana: hay que poder controlar las entradas y salidas. De ahí que los dos elementos fundamentales de todo cerco urbano sean la pared (función unopason) y las puertas o entradas al poblado (función "paso controlado").

La situación orográfjca condiciona mucho la naturaleza del cerco. Las poblaciones tienden a tener una parte de su recinto en alturas sobre relieves de difí- 
cil acceso, para acentuar el carácter defensivo del cerco len cambio el agua, fluvial o marítima, no garantiza suficientemente el «no-paso» y exige murallas marítimas especiales). Significativamente, las fuentes árabes nos dicen que Valencia tenía muy fuertes murallas; en llanura y con un río de fácil acceso, tenía que compensar esta situación orográfica estratégicamente débil con un cerco de mano humana reforzado.

Fuera del recinto y cerco de la población, hay dos zonas relativamente bien diferenciadas: la zona periurbana y el campo abierto.

La zona periurbana (podríamos llamarla en árabe dawâhi o "suburbios", generalmente poco habitados, que no hay que confundir con los arrabales Irabadj, parte integrante del recinto urbanol, tiene generalmente elementos específicos: las huertas que alimentan a la ciudad (el fahs o "campo de cultivo"), muchas veces con sus núcleos de población propios; los cementerios - maqâbir - lque pueden estar también en el interior del cerco y en el recinto cercado de la ciudad, si éste ha tenido una ampliación o abarca más que el terreno habitado, por razones estratégicas); los mercadillos (suwaiqa) de las puertas, de productos agrícolas generalmente perecederos, lugar de intercambio entre el campo y la ciudad, que se desmonta cada noche o no se monta más que en un determinado día de la semana; algunas "industrias", sobre todo las "polucionantes" (curtidos, cerámica...), que requieren abundancia de agua (molinos...) o la producción de sal marina (que a veces están incluidos en el interior de los recintos urbanos, por razones estratégicas), etcétera.

Espacialmente, hay pues que distinguir a su vez tres zonas en este espacio periurbano: campos de cultivo, campos de transacciones humanas (viviendas rurales o palacios de recreo, mercadillo, "industrias", cementerios y otros eventuales lugares de culto y devoción religiosa) y superficies acuáticas (mar, río, fuentes). Este espacio acuático periurbano será acercado lo más posible al recinto urbano por defensas específicas y por sistemas subterráneos u otros de captación de agua potable, para diversos servicios urbanos (alimentación; lavado corporal, de ropa y otros; artesanía; regadío de jardines domésticos y palaciegos; etcéteral.

El campo abierto, que no cae directamente en el espacio urbano, aunque esté controlado por la ciudad, tiene a su vez unos espacios especificos: las vías de comunicación entre núcleos de población o regiones; los terrenos de pastoreo y de agricultura de subsistencia seminómada; algunos sitios de encuentro o mercados rurales (cuando no están en las puertas de los núcleos urbanos); sistemas militares de vigilancia y defensa de territorios y vias de comunicación; algunos lugares de depredación simple de materias primas (madera y caza de bosques, minas, quizás agricultura extensiva o arboricultura silvestre); vías fluviales y marítimas (comunicación y transporte; depredación piscícola y coralífera); etcétera.

Conviene advertir que todas las zonas rurales están controladas por el poder político de las ciudades, representado por castillos en una red más o menos densa, según el peligro de poderes políticos enemigos; ese control se ejerce sobre todo por expediciones fiscales periódicas.

Estas tres zonas urbanas tienen, por tanto, una referencia común: el recinto urbano y sus accesos a través del cerco. Estos son objeto de un particular sistema de control, especialmente de noche: no se permite la entrada (cierre de puertas, vigilancia armada) y se controla de día las salidad (que no salga producto de ro- 
bos, ni mujeres solas) y entradas (extranjeros, rurales...). La función específica de los cercos y de sus accesos da amplio lugar al estudio de sus peculiaridades arquitectónicas, que ha dejado en España más huellas arqueológicas de lo que se piensa, si se estudian estos espacios de forma global y complementaria.

Estos espacios están relacionados además por vías de comunicación, cuya trama determina muchos de los elementos morfológicos del urbanismo musulmán, que es generalmente radioconcéntrico, frente al entramado en forma de damero del urbanismo romano (como puede estudiarse en la evolución de la capital de Malloreal.

\section{El modelo supremo de ciudad: la capital o metrópoli}

Se puede afirmar que hay un modelo islámico de ciudad, patrón al que tiende toda aglomeración urbana y que vamos a intentar exponer en toda su complejidad. Evidentemente, no todo poblamiento musulmán logra tener todos sus elementos diferenciados.

El modelo ideológico de ciudad es evidentemente Medina, "La Ciudad del Profeta», pero en su simplicidad inicial confunde urbanísticamente todos los elementos diferenciadores: la casa privada de Mahoma es al mismo tiempo sede de gobierno y mezquita de la comunidad. Este modelo tiene en germen todos los elementos del desarrollo futuro de la ciudad, que se daba ya en la realidad no ideológica de La Meca y de la propia Medina contemporáneas. Pero el verdadero modelo urbanístico lo dan los grandes recintos con cercos murados, que la terminología árabe llama âssima, "capital», "metrópoli" (etimológica y significativamente "la que protege y da refugion), de las que Al-Idrisi, en el siglo XII, sólo encuentra en Al-Andalus a Córdoba, Sevilla, Valencia y Zaragoza. También figuran en este modelo supremo, aunque sean más pequeñas, las "ciudades" (madina)

En una medina, o ciudad interior al cerco, se pueden hacer tres clases de divisiones espaciales, urbanísticamente significativas.

La primera es diferenciar el núcleo urbano (madina, en sentido restringido) y arrabal rabad) (esquema 2). El o los arrabales son núcleos urbanos casi autónomos, con su cerco propio, anexos al núcleo central y con casi todos sus elementos, menos las relaciones con el centro de poder político. Suele nacer de un aumento rápido de población, alrededor de las vías de acceso a las puertas de la ciudad antigua y a veces separado de ella por un río (Córdoba, Málaga, Elche, etcéteral.

La segunda división se refiere precisamente a ese centro del poder: hay una ciudad político-militar (con su castillo o alcazaba [qasaba) y/o su alcázar o palacio [qașr]l) diferenciada de la ciudad civil (madina, también en sentido restrictivo) (esquema 3).

Nos detendremos especialmente en esta división y expondremos al final las características de los centros político-militares.

\section{La ciudad civil: los barrios de residencia, sus casas y sus accesos}

Es sumamente importante, en urbanismo musulmán, distinguir los barrios de residencia (hawma, pronunciado homa) de los espacios públicos. Estos es- 
tán constituidos por las vías de comunicación (del centro a los accesos del recinto; de unos barrios con otros); las mezquitas y los centros de enseñanza; los baños; los zocos o mercados; los hornos. Son espacios en los que está absolutamente excluida la residencia, es decir los hogares con mujeres y la habitación nocturna (salvo, excepcionalmente para algunos individuos, en los baños y funduq). En cambio, los barrios o umanzanas" residenciales son espacios urbanisticos aislados, entre las vías de comunicación internas de la ciudad, totalmente diferenciados de los espacios públicos o de acceso público (esquema 4). Estos barrios de residencia lo constituyen las casas, sus vías de acceso y algunos servicios comunes del barrio (mezquita, escuela, comerciante, horno, baño, peluquería), situados generalmente en la confluencia entre las vias de comunicación generales y las vías de acceso comunes a las casas (esquema 5 ).

Luego examinaremos la estructura de cada casa. Pero las casas no están unidas directamente a la red general de comunicaciones urbanas. Esa unión pasa por unas vias de acceso comunes a varias casas, estrechas y tortuosas (zuqâq), que acaban generalmente en callejones sin salida (darb) y que dan a la ciudad árabe un carácter laberíntico, incomprensible para los que no conocen la razón de ser de esas vías de acceso. Son callejones privativos de esas casas, no son calles públicas. Su acceso está en parte controlado, porque no son vías de tránsito, sino de acceso a unas casas determinadas. Tienen la función equivalente, en las ciudades españolas, a los accesos de una urbanización privada (con sus jardines, aparcamientos, tiendas, etc.) o, mejor dicho, como un edificio de pisos, con su zaguán, escaleras, ascensores, etcétera, para acceder a los apartamentos o casas. Esas vías de acceso son semipúblicas o de acceso. No hay, por tanto, que confundirlas con las calles que unen diversos barrios de la ciudad (que son relativamente rectas, anchas y largas, con tráfico diurno continuo y muchas zonas de permanencial, mientras que aquéllas son estrechas, tortuosas, sin salida, de paso rápido y tráfico escaso. También se observan diferencias entre los (islotes" residenciales de la medina y los de los suburbios, a veces más rectilíneos, al igual que los adarves de los límites del recinto.

Las casas corresponden, sobre todo si son de calidad, al sistema de patio central, al que dan las habitaciones (salas de estar y dormir), la cocina, los evacuatorios y el acceso a la casa len forma de codo ylo al menos con una cortina que deje pasar el aire, pero no las miradas indiscretas desde la calle) (esquema 6). A veces, y en zonas rurales, el patio no está cerrado por habitaciones en todos los lados, sino por paredes, que encierran un huertecillo y/o un corral lesquema 71 .

Las habitaciones, en su máximo desarrollo, están en forma de "T», con un elemento central frente a la puerta de acceso al patio, que puede servir de sala de recepción al dueño de la casa, de biblioteca y exposición de adornos, y con los lechos en los demás rincones, con almacenes especialmente para la ropa (esquema 7). Este "modelo operativo" del espacio doméstico puede ofrecer, evidentemente, muchas formas concretas de realización. La cocina tiene como elementos esenciales el fogón y los depósitos de alimentos i utensilios. El fogón puede ser muy sencillo y hasta de cerámica transportable al patio o brasero (según la estación del año), que se complementa con el horno del barrio, para cocciones más complejas (pan, pasteles, etc.). Muy importante en el esquema urbanístico de la casa es el sistema de suministro de agua (por acarreo manual, por pozos, por acequias, por algibes de aguas pluviales...) y de los evacuatorios, según la calidad de la casa. Es evidente que los palacios, sede del poder político - de los que se hablará más adelante-poseen más dependencias, pe- 
ro siempre como desarrollo, en forma modular, del modelo general de casas árabes.

Ya se ha mencionado una serie de instituciones comunes al o a varios barrios residenciales: un comerciante que vende de todo, especialmente alimentos al por menor y objetos sencillos de uso doméstico (no suele residir en el. barrio y tiene su tienda en una esquina, a la entrada de una o varias vias de acceso); una mezquita más o menos importante (masyid); una escuela de primeras letras (kuttáb); un horno (furn); un baño (hammâm) (con su amplia sala de vestirse y descansar, sus recintos húmedos y calientes con gruesos muros, sus balsas de agua caliente y fría, su horno y conducciones de agua, sus terrazas para secar las toallas); un peluquero masculino (también circuncisor, sangrador y ucronista local», que puede estar a la entrada del barrio o de vías de acceso, o agrupados varios juntos cerca de los accesos a la ciudad); una fuente pública de agua potable.

Estos servicios pueden ser comunes a varias "manzanas". Son de fácil acceso para los habitantes de las casas, pero exigen "salir de casa" o enviar a unla chiquillo/a para comprar (mercader, horno), o a arreglarse para salir (baño, mezquita).

Como se va a ver, la estructura y funcionalidad urbanística de los barrios residenciales son totalmente diferentes de los espacios públicos. Corresponden, en proyección horizontal, a nuestros inmuebles de pisos, en los que sólo hubiera apartamentos $y$ no oficinas, con una serie de tiendas y servicios en la planta baja.

\section{Los diversos mercados de intercambio y de producción artesanal}

Dentro de los espacios públicos de la ciudad musulmana, hay que señalar en primer lugar, por su importancia, su extensión y su diversidad, los mercados, centros principalmente comerciales, aunque pueden asumir también otras funciones. Los catalogaremos en categorias diversas: mercadillos a la entrada de la aglomeración, mercader de barrio, vendedores y vendedoras ambulantes, zocos artesanales, alcaicerías "estatales", alhóndigas o fondas, industrias polucionantes, alcaicerías (esquema 8 ).

Puede afirmarse que, morfológicamente, en todos los mercados se yuxtaponen las "tiendecillas" homogéneas en forma lineal la lo largo de una misma vía) o más específicamente nodal (con vías secundarias perpendiculares, en forma reticular).

Ya se ha hablado del espacio abierto, a la puerta de las ciudades y puertos, donde se desarrolla el mercadillo (suwaiqa), con predominio de intercambio entre la ciudad y el campo (importación de productos alimenticios, de materia y de productos manufacturados, del campo a la ciudad; servicios de la ciudad a tos rurales, ya en el interior de la ciudad, pero cerca de las puertas - vestidos y utensilios, ferretería, guarniciones para caballerizas, prostíbulos, etcétera -1 . Sus funciones se reproducen hoy en dia, en muchos pueblos y ciudades alicantinos, por ejemplo. Como aquí, pueden tener unos días semanales fijos o desmontarse y montarse cada dia. Esas plazas, que pueden tener también otras funciones (por ejemplo, lúdicas en desfiles, fiestas y diversiones), quedan enteramente desnudas por las noches. 
También se ha hablado del mercado de barrio, en una esquina de los accesos a las casas. Si hay confluencia de barrios, puede haber varios mercados. En relación con este comercio de detallista están los mercados ambulantes: pueden ser hombres, en toda clase de lugares de tránsito de la ciudad (ya sea en la entrada o en los zocos artesanales o en las vías generales de comunicación 1, o mujeres, que van de casa en casa, ya sean ciudadanas con productos artesanales, o rurales con productos del campo. Estos no dejan, obviamente, huellas aparentes en el espacio urbanístico, pero hay que tenerlos en cuenta.

Los zocos artesanales se concentran en el centro de la ciudad (para una clientela esencialmente urbana) o cerca de las puertas (para una clientela urbana y rural conjuntamentel. Cada "tienda" tiene una superficie muy reducida (generalmente entre 4 y 6 metros cuadrados), lo que permite una acumulación de comerciantes yuxtapuestos a lo largo de una misma vía o zoco, con venta de un mismo producto. Venden productos no perecederos y no polucionantes (Iibros, frutas secas y especias, joyas y perfumes, productos vestimentarios de toda clase, ferretería, etcétera). Muchas veces venden y producen en el mismo sitio, si la transformación de las materias primas no resulta muy polucionante. Si no, se trasladan a las afueras de la ciudad o tienen zocos propios cerca de las puertas (carpinteros, tintoreros, curtidores, jabonerías, ceramistas...). También cerca de las puertas están zocos de transformación directa de productos agrícolas voluminosos: esteras, esparto... Los vendedores de un mismo producto pueden y suelen agruparse en tiendas contiguas, en la misma calle, que tomará el nombre de zoco de tal profesión. Los barrios que ocupan esos zocos no admiten generalmente residencias, por lo que se cierran con puertas y con vigilantes, durante la noche. Algunos zocos más relacionados con la mezquita (libreros, perfumistas, testigos y notarios, etcétera) y que no molestan a la actividad del santuario, se sitúan cerca de ese edificio, mientras que los de productos de mayor avalor añadidon (joyeros, vestidos de lujo, esclavos $\gamma$, sobre todo. las alcaicerías de producción monopolística del Estado) suelen estar más cerca del alcázar o centro del poder.

Las alcaicerias o conjuntos urbanísticos comerciales y artesanales constituidos por el poder político, que los arrienda por alto precio en régimen de monopolio de producción y venta, forman barrios propios dentro del barrio comercial, donde hay una máxima utilización reticular del espacio, en el centro de la ciudad. Esos monopolios pueden ser de joyas y objetos preciosos, de vestidos de lujo, de seda (Granada), de bonetes de lana (Túnez), etcétera. Puede haber una "alcaicería grande" y una "alcaicería pequeña", a veces muy juntas.

Los funduq (fonda o alhóndiga) son edificios especiales, con una especialización en un comercio que podríamos calificar de "al por mayor". Puede haber alhóndigas de productos no polucionantes (carbón, cereales, aceite...) o de productos comerciales de importación (en las entradas de las ciudades y puertos). Morfológicamente, suelen tener un amplio patio central acolumnado, con un piso superior con balaustrada. El ejemplo español más característico es el Corral del Carbón, en Granada, de época árabe nazari. Fuertemente custodiadas, pueden servir también de residencia temporal (de ahí la palabra castellana "fonda») a comerciantes, harrieros, etcétera, cuando son alhóndigas en las entradas de la ciudad.

El puerto produce, evidentemente, unas estructuras urbanísticas propias, dentro de las características de los lugares públicos de intercambio y producción de la ciudad: estructuras de atracaderos, ațarazanas con materiales de fa- 
bricación y reparación de buques, depósitos de mercancías, alhóndigas de todas clases, aduanas o servicios de control y fiscalidad de las importaciones, etcétera.

En este breve esquema no se puede desarrollar el proceso complejo de cada sector comercial (más de cuatrocientos, según estudio en Marrákesh), desde la obtención de la materia prima, su transformación artesanal y su venta al por mayor, al detalle y a la exportación, así como la función de reparación de productos manufacturados de segunda mano. Es evidente que cada género tiene un desarrollo particular que produce ocupaciones diferentes del espacio urbano, pero generalmente dentro del "modelo operativo" que se acaba de presentar. Hay que señalar que, a pesar del fraccionamiento del comercio, que funciona con muy poco capital individual, la concentración urbana (la ciudad como centro de intercambios territoriales), propia de la sociedad musulmana, provoca una fuerte demanda y una rotación muy rápida de esos pequeños fondos del comercio de las ciudades.

\section{Mezquitas o centros religiosos}

La mezquita, ya desde los orígenes del Islam, ocupa un lugar central en el urbanismo musulmán. Es ella la que ha generado, por especialización de sus funciones, otros muchos edificios y lugares religiosos, dentro y fuera de la ciudad. Consideraremos lo "religioso" en su más central especificidad lque no tiene en el Islam) y lo veremos en la "mezquita aljama" central, antes de ver sus prolongaciones en la ciudad, según las épocas y la magnitud de esas poblaciones.

La mezquita aljama o principal de una ciudad es el lugar de reunión de los fieles para la oración del viernes al mediodía, en la que oirán el sermón o discurso político-religioso obligatorio. Las demás oraciones obligatorias de la semana (cinco diarias) pueden hacerse en cualquier otro sitio "puro" (en casa, en el campo, en mezquitas de barrio, en las tiendas...). Pero hay quien las hace también en la mezquita aljama. Ha de ser amplia, para poder albergar el viernes a todos los fieles y sobre todo a todas las autoridades y responsables públicos con su séquito. Puede haber en una ciudad otras mezquitas importantes, con predicación, si las distancias son grandes entre los barrios y si la población no cabe en la mezquita aljama ssobre todo en mezquita de palacio y mezquita de arraball, pero la mezquita aljama es la mezquita política por excelencia, para las autoridades supremas.

Después de la oración del viernes y aprovechando que los hombres están alli reunidos, en la mezquita se hacen los contratos, especialmente los de bodas, y se resuelven litigios políticos y jurídicos (Tribunal de las Aguas de Valencia), aunque estas funciones jurídicas pueden quedar relegadas a otras dependencias urbanas vecinas (palacio real, casa del juez, barrio de notarios y testigos, etcétera).

También en la mezquita se da la enseñanza, sea en la misma sala acolumnada de la oración, sea en los soportales del patio adjunto. Pero esta enseñanza de la mezquita se da también al lado de ella en edificios especiales para la enseñanza primaria de los niños, también en sus propios barrios, aunque generalmente siempre al lado de una mezquita. En el bajo Medioevo, también se crearon centros de enseñanza especiales, con residencia de estudiantes llas madrasa, como las de Granda y las merinies de Marruecos). 
En la sala de la mezquita se realizan también sesiones especiales de devoción, sobre todo las noches del mes de Ramadán, con lecturas del Corán. Esta función de la mezquita se traslada a veces a mezquitas de barrio o de palacios particulares $y$, en formas ya más desarrolladas, en sedes de "cofradias" o escuelas místicas bajo la dirección de maestros espirituales o en mausoleos de personajes santos, dentro o fuera del recinto urbano, en cementerios.

La mezquita, cuyos elementos funcionales no vamos a pormenorizar aquí, tiene elementos comunes a las casas residenciales, las alhóndigas y la construcción con patio central en general les el módulo simple fundamental en la construcción islámica). Habría que estudiar sus principales elementos arquitectónicos: la pared recta orientada a La Meca, con su nicho del director de la oración; su sala cubierta, con el púlpito, las zonas acotadas y los accesos al patio y a las calles que la rodean; el minarete o torre alminar; el patio y sus columnatas cubiertas; el sistema de captación de agua (algibe, alberca...) para los evacuatorios y las fuentes de purificación; los zocos de sus alrededores, generalmente también en los bajos de la mezquita o contiguos a sus paredes; los sistemas viarios de acceso a la mezquita, que centraliza la red viaria principal de la ciudad; etcétera (esquema 9).

Religiosamente relacionado con la mezquita está el baño (thammàm), donde se hace la purificación mayor de ablución o limpieza de todo el cuerpo, como se hacen las abluciones menores en las fuentes, grifos y evacuatorios de la propia mezquita o en casa. Pero así como los elementos para hacer purificación menor pueden hallarse en las dependencias o patio de la mezquita (el mída'a), el baño de las purificaciones mayores, que exige agua caliente para la limpieza de todo el cuerpo, está generalmente desvinculado físicamente de la mezquita y más cerca de los barrios residenciales fla proporción de baños con mezquita en la ciudad de Monastir, antes de las reformas urbanisticas de 1956, eran de cuatro baños frente a quince mezquitas). Como está en preparación un libro colectivo sobre los baños en el País Valenciano, no es preciso entrar en detalles sobre los espacios del baño y sus funciones.

\section{La ciudadela político-militar: alcázares y castillos}

Dentro de la ciudad musulmana, hay toda una gama de espacios específicos del poder político-militar: desde los modestos castillos que controlan una zona rural hasta las ciudades dentro de la ciudad, que la dominan (Alhambra de Granada) o están en el centro mismo de la ciudad civil (Almudaina de Palma de Mallorca o Alcázar de Valencia). Hay que incluir también en este espacio urbanístico a las almunias y otras residencias placenteras extramuros, en la huerta periurbana (el palacio de Monteagudo, en Murcia; los Reales de Valencia...) a donde se traslada muchas veces y por largo tiempo el poder (esquema 3 ).

El estudio de estos variados espacios, sede del poder político-militar en la ciudad y en la sociedad islámica en general, no es fácil y resulta complejo. Pero no puede dejarse de mencionar, porque es elemento esencial de la ciudad, elemento diferenciado y complementario de todos los demás.

La ciudadela, en sus diversas formas, tiene una estructura fuertemente individual, como órgano extranjero injertado en el cuerpo urbano. Tiene recinto propio, con cerco particularmente reforzado, por su posición y sus construcciones, con fortificaciones y accesos propios, tanto frente a la ciudad civil como a 
su contorno. Ese espacio tiene que dar cabida a una guardia militar más o menos numerosa. Tiene que tener prácticamente todos los servicios de un barrio o suburbio civil, al menos en las grandes ciudades (mezquita, hornos, baños, mercados...). Tiene numerosas estancias adosadas, articuladas como módulos yuxtapuestos de casas residenciales, también articuladas con estancias de recepciones y de "trabajo administrativo". Son los alcázares de las capitales árabes y -en menor medida - de las residencias urbanas y periurbanas de los altos funcionarios.

En el campo, la estructura de las fortalezas incluye el "albacar" o lugar de conservación del ganado, como he estudiado en el número precedente de esta revista.

Vale la pena esbozar las modificaciones que una labor política da al modelo general de una casa musulmana, en los alcázares administrativos del poder político-militar (esquema 101. En principio, los elementos de recepción, en los accesos y en las estancias del patio, se desarrollan: la entrada en codo se alarga y adorna, para filtrar allí a los que vienen a obtener audiencia; la sala en "T" $Y$ el patio adyacente se amplían, con mayores asientos y más adornos en las paredes, artesonados y columnatas.

También los servicios generales (oratorios-mezquitas, cocinas, baños, evacuatorios...) se amplían y multiplican, ya que han de prestar servicio a una población que supera ampliamente a una familia, por muy amplia que sea. Las capacidades financieras del poder político-militar, generalmente muy poderosas tanto para adquirir materiales de construcción como mano de obra más o menos cualificada, hacen que esas residencias puedan presentar formas urbanísticas muy diversas, fruto de constantes y muy importantes modificaciones arquitectónicas. Esto se ha de ponderar, evidentemente, en función de la importancia de la población y de su poder político-militar, en las diversas épocas de la historia de una ciudad musulmana.

\section{Conclusión}

Estos son los principales elementos de este "modelo operativo» de urbanismo musuimán.

No queremos terminar sin agradecer a los colegas del grupo de "Urbanismo Musulmán" su aliento y colaboración, y especialmente al arquitecto-conservador Màrius Bevià por la realización práctica de los esquemas que presentamos aqui. 

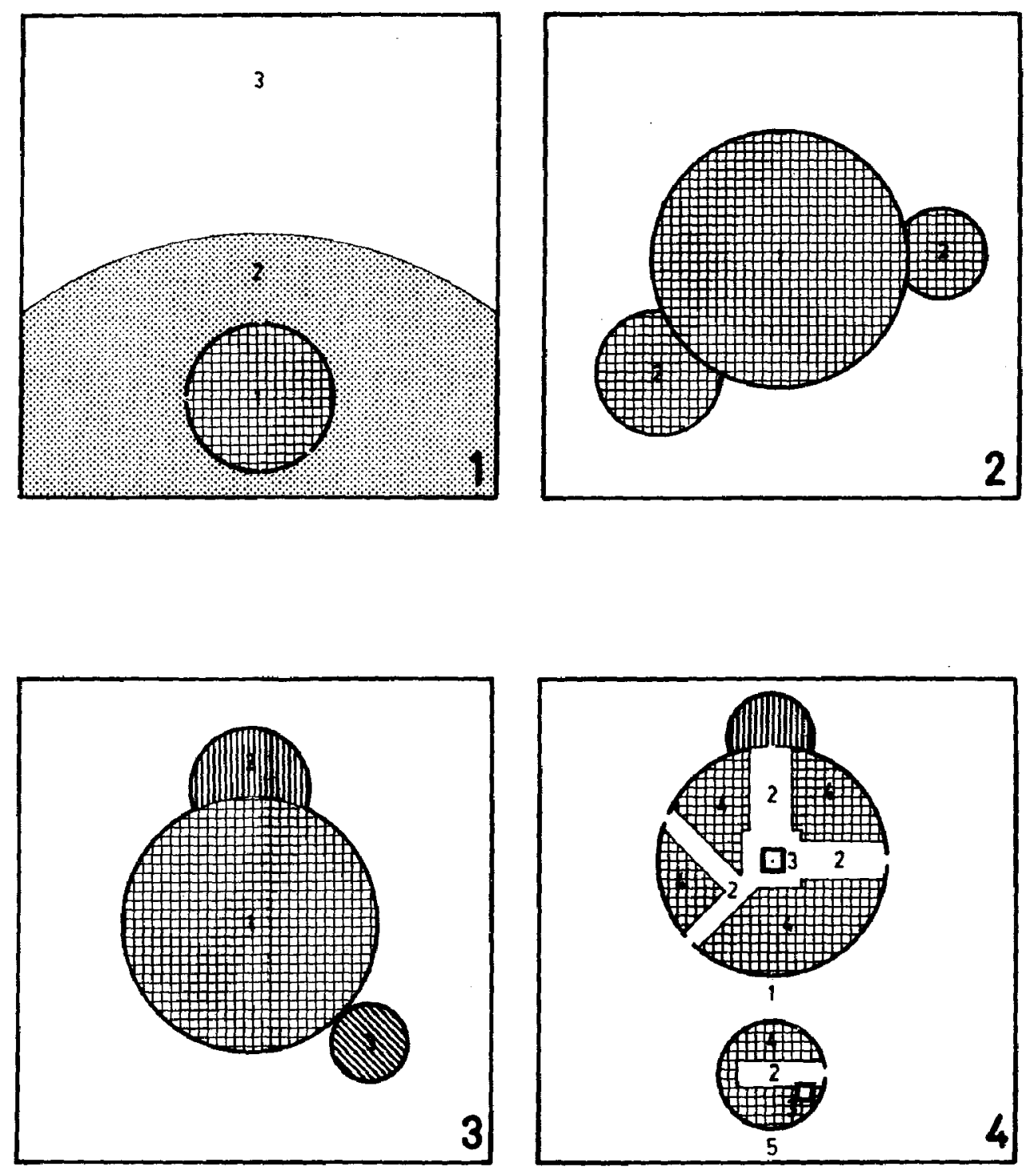

Fig. 1. - Tres espacios geográficos urbanos: 11 Núcleo urbano y su recinto. 21 Zona periurbana. 31 Campo abierto

Fig. 2. - La medina y sus arrabales: 11 Medina. 2i Arrabales.

Fig. 3. - La ciudad politico-militar y la ciudad civil: 1/ Medina. 21 Qașr o alcázar. 3) Oașaba o alcazaba.

Fig. 4. -Espacios de residencia, en urbe y en pueblo: 1) Urbe. 2) Vias principales. 3) Mezquita mayor 0 aljama. 4) Bairios Residenciales. 5) Pueblo o hábitat menor rural. 

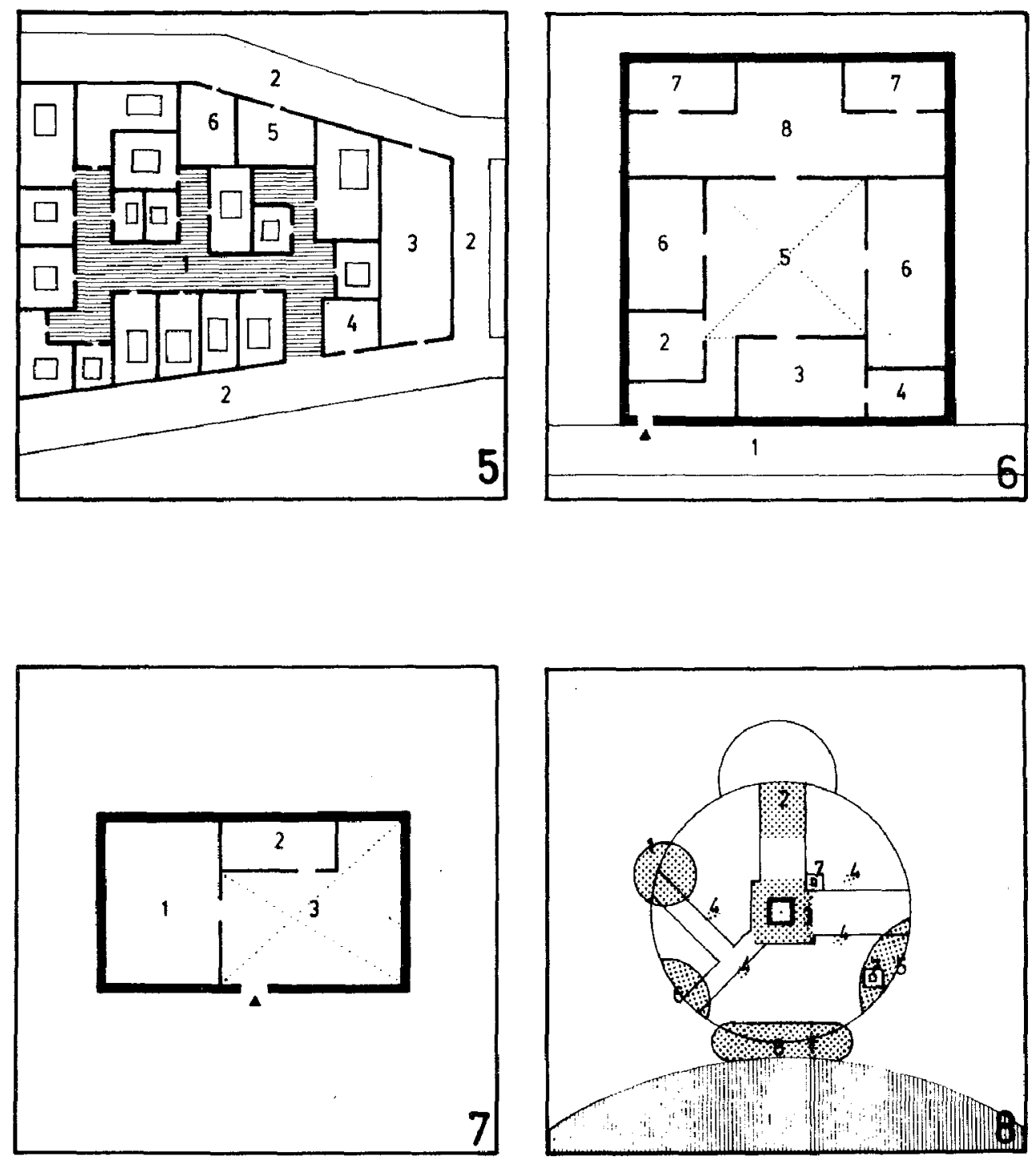

Fig. 5.-Barrio o umanzanan residencial: 1 ) Calle de acceso del barrio. 21 Vias principales. 3) Mezquita de barrio 4) Mercader o barbero. 5) Baño. 6) Horno

Fig. 6. - Las casas de ciudad: 11 Calle de acceso. 2) Mezquita doméstica. 31 Cocina. 4l Evacuatorio. 5) Patio. 6i Ha bitaciones. 71 Dormitorio o almacén. 81 Habitacłón, recepción, biblioteca

Fig. 7.--Las casas furales: 1 I Habitación. 2/ Corral. 31 Patio y/o huerta.

Fig. 8.-Diversos mercados: 1 ) Mercadilo de puerta o acceso. 2) Alcaiceria de monopolios. 3) Zocos o mercados artesanales. 4| Mercaderes ambulantes y de barrio. 51 Zocos artesanales polucionantes. 61 Zocos artesanales y mercadillos para rurales. 71 Fúnduq o alhóndiga. 81 Puerto. 

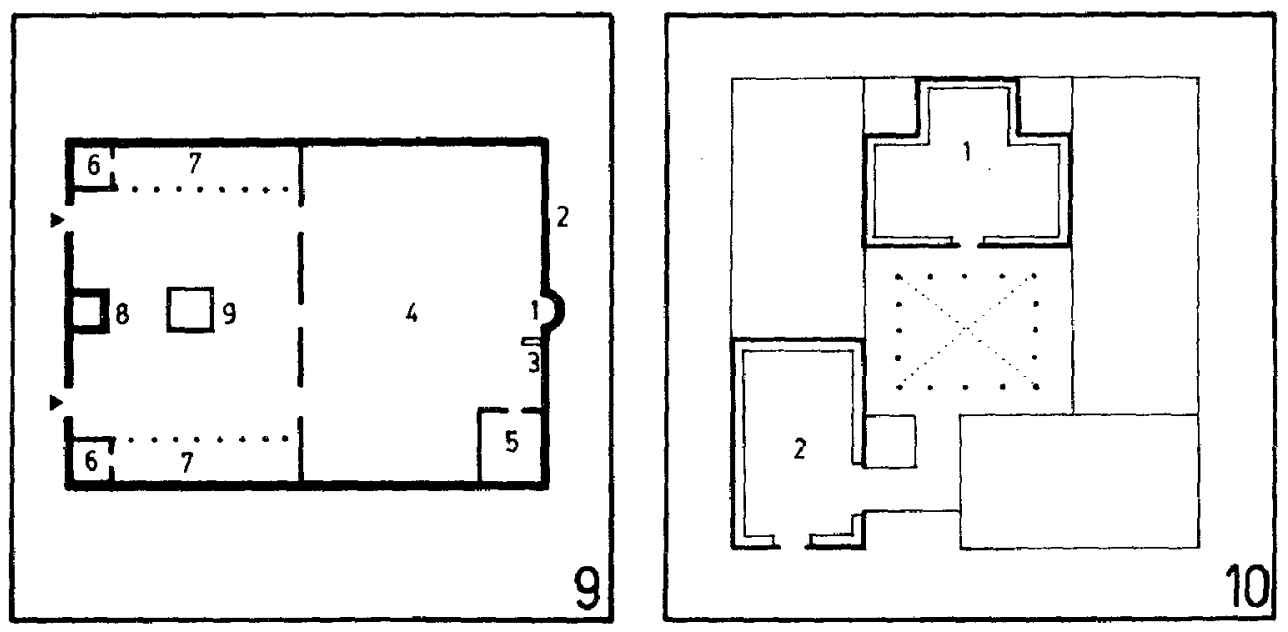

Fig. 9.-Mezquita: 1$)$ Mínsab o nicho. 2) Quibla o muro de orientación 31 Minbar o púlpiro. 4) Sala cubierta. 51 Maqsūra o lugar reservado. 6) Evacuatorios y fuentes de abluciones. 7) Columnatas. 8) Minarete o almınar 9) Fuente y/o algibe.

Fig. 10. - Salas de recepción: 1 y 21 Salas con asientos adosados 